\title{
Caracterização molecular de Sarcocystis spp. em amostras de carne ${ }^{1}$
}

\author{
Marta E.M. Alves ${ }^{2 *}$, Gustavo C. Cadore ${ }^{2}$, Caroline S. Oliveira² ${ }^{2}$ Luiza P. Portella ${ }^{2}$, \\ Luis A. Sangioni' ${ }^{2}$ e Fernanda S.F. Vogel ${ }^{2}$
}

\begin{abstract}
Alves M.E.M., Cadore G.C., Oliveira C.S., Portella L.P., Sangioni L.A. \& Vogel F.S.F. 2018. [Molecular characterization of Sarcocystis spp. in samples of meat.] Caracterização molecular de Sarcocystis spp. em amostras de carne. Pesquisa Veterinária Brasileira 38(3):425-429. Departamento de Medicina Veterinária Preventiva, Centro de Ciências Rurais, Universidade Federal de Santa Maria, Av. Roraima 1000, Prédio 44, Sala 5149, Bairro Camobi, Santa Maria, RS 97105-900, Brazil. E-mail: marta.elenamachado@gmail.com

The sarcocystosis is a worldwide spread disease and can affect birds, reptiles and many mammals, including man. The aim of this study was to detect the presence of Sarcocystis spp. and characterize the species found in 375 samples of meat products (filet mignon, ground beef and colonial salami). For this, we carried out the detection of the parasite by PCR for the amplification of the partial 18S rRNA gene and molecular characterization using the restriction fragment length polymorphism (RFLP) with restriction enzymes Bcl I, Alu I and Rsa I. The occurrence of Sarcocystis spp. was 17\% (64/375) of all samples. Among the meat products evaluated, the filet mignon samples were positive in $5.6 \%(7 / 125)$, the ground beef in $12.8 \%(16 / 125)$ and the colonial salami in $32.8 \%$ (41/125). Of the positive samples, Sarcocystis hirsuta and Sarcocystis hominis were detected, with prevalence of $93.7 \%(60 / 64)$ and $6.3 \%(4 / 64)$, respectively. Considering the relevance of sarcocystosis in public health, the occurrence of $S$. hominis found may be a risk factor to human contamination. However, the presence of DNA of this parasite does not necessarily mean potential of infection to humans, because good practices in the manufacturing processes can reduce the viability of the cysts. INDEX TERMS: Sarcocystis spp., meat, 18S rRNA, food security, meat products, restriction enzyme, sarcocystosis, parasitoses.
\end{abstract}

RESUMO.- A sarcocistose é uma doença distribuída mundialmente, podendo acometer aves, répteis e diversos mamíferos, incluindo o homem. 0 objetivo desse trabalho foi detectar a presença de Sarcocystis spp. e caracterizar as espécies encontradas em 375 amostras de produtos cárneos (filé mignon bovino, carne moída bovina e salame colonial). Para isso, foi realizada a detecção do parasita através da técnica de PCR para amplificação parcial do gene 18S rRNA e sua caracterização molecular utilizando o polimorfismo no comprimento do fragmento de restrição (RFLP) com as enzimas de restrição Bcl I, Rsa I e Alu I. A ocorrência de Sarcocystis spp.

\footnotetext{
${ }^{1}$ Recebido em 16 de fevereiro de 2016.

Aceito para publicação em 31 de janeiro de 2017.

${ }^{2}$ Departamento de Medicina Veterinária Preventiva (DMVP), Centro de Ciências Rurais (CCR), Universidade Federal de Santa Maria (UFSM), Av. Roraima 1000, Prédio 44, Sala 5149, Bairro Camobi, Santa Maria, RS 97105-900, Brasil. E-mails: gustavocadore@yahoo.com.br, carolsobotyk@gmail.com, lupiresportella@gmail.com, fefevogel@gmail.com, lasangioni@gmail.com; *Autor para correspondência: marta.elenamachado@gmail.com
}

foi de $17 \%(64 / 375)$ do total de amostras testadas pelo PCR. Entre os produtos cárneos avaliados, 5,6\% (7/125) das amostras de filé mignon, $12,8 \%(16 / 125)$ de carne moída e $32,8 \%(41 / 125)$ de embutido colonial, foram positivas para presença do DNA do Sarcocystis spp. Entre estas amostras positivas, as espécies caracterizadas foram Sarcocystis hirsuta e Sarcocystis hominis com prevalências de 93,7\% (60/64) e 6,3\% (4/64), respectivamente. Considerando à relevância da sarcocistose na área da saúde pública, a ocorrência de $S$. hominis encontrado neste estudo, pode ser um fator de risco para a contaminação humana. Porém, a presença do DNA deste protozoário não significa necessariamente potencial de infecção aos humanos, pois cuidados nos processos de fabricação podem reduzir a viabilidade dos cistos.

TERMOS DE INDEXAÇÃ̃O: Sarcocystis spp., carne, 18S rRNA, segurança alimentar, produtos cárneos, restrição enzimática, sarcocistose, parasitoses. 


\section{INTRODUÇÃO}

0 protozoário do gênero Sarcocystis spp. é um parasita intracelular obrigatório, sendo importante principalmente em animais de produção, devido o seu ciclo de vida estar diretamente relacionado com o consumo da carne destes animais (Dubey \& Lindsay 2006). O Sarcocystis cruzi, Sarcocystis hirsuta e Sarcocystis hominis tem como hospedeiro definitivo cães, gatos e primatas, respectivamente, sendo o hospedeiro intermediário o bovino. No ciclo de vida de Sarcocystis suihominis o homem é o hospedeiro definitivo e os suínos são os hospedeiros intermediários (Ruas et al. 2001). Duas espécies são consideradas zoonóticas para o homem, S. hominis e $S$. suihominis, onde a infecção ocorre pela ingestão da carne ou produtos cárneos dos hospedeiros intermediários crus ou mal cozidos contendo cistos do protozoário (Rommel 1985). Geralmente a infecção não produz um quadro sintomático grave, sendo os sinais clínicos bastante variáveis de acordo com o grau de infecção (Italiano et al. 2014). Porém as manifestações clínicas costumam ser evidenciadas quando a infecção é causada pelo $S$. suihominis em pacientes imunocomprometidos (Reys 2008).

Os produtos cárneos consumidos crus ou mal cozidos são considerados alimentos de alto risco epidemiológico na veiculação de agentes patogênicos (Germano \& Germano 2001, Dubey \& Lindsay 2006), e dentre estes produtos disponíveis ao consumo humano, podemos citar o filé mignon, a carne moída e o salame colonial. 0 filé mignon bovino é um corte bastante utilizado para a confecção do Carpaccio, geralmente encontrado em bares e restaurantes, o qual consiste em finas fatias de carne crua (Lucquin et al. 2012). A carne moída bovina é um produto que pode ser utilizado para o preparo de quibe cru (Braga \& Ferreira 2013), e o salame colonial, é um derivado cárneo produzido por processos de cura e fermentação, produzidos com carne suína e bovina ou apenas suína (Silva et al. 2011). Sendo assim, por serem consumidos crus estes alimentos podem apresentar riscos à saúde pública podendo veicular diversos parasitas, entre eles o Sarcocystis spp.

Para realização do diagnóstico, o uso de técnicas moleculares é uma ferramenta importante na investigação epidemiológica da sarcoscistose. Diversos estudos utilizam a reação em cadeia da polimerase (PCR) com amplificação do gene 18S rRNA para o diagnóstico de infecções por Sarcocystis spp., com ênfase na identificação das espécies utilizando sequenciamento e/ou a técnica de polimorfismo no comprimento do fragmento de restrição (RFLP) (Yang et al. 2002, Stojecki et al. 2012). Neste estudo, o objetivo foi detectar a presença do Sarcocystis spp. e realizar a caracterização molecular das espécies encontradas em 375 amostras de produtos cárneos (filé mignon bovino, carne moída bovina e salame colonial).

\section{MATERIAL E MÉTODOS}

Os produtos cárneos foram adquiridos em 18 estabelecimentos comerciais (10 açougues e 8 mercados) e em 15 feiras livres da cidade de Santa Maria, Rio Grande do Sul. Um total de 375 amostras foram avaliadas (125 amostras de filé mignon bovino, 125 amostras de carne moída bovina e 125 amostras de salame colonial). A carne moída e o filé mignon foram adquiridos em estabelecimentos comerciais, com diferentes níveis de inspeção sanitária (municipal, estadual e federal). As amostras de salame colonial apresentavam origem mista (produzido com carne suína e bovina) sendo adquiridas de feiras livres, que possuíam inspeção sanitária municipal. Durante o transporte, o material coletado foi armazenado em caixas isotérmicas refrigeradas e posteriormente congeladas a $-20^{\circ} \mathrm{C}$ até a realização da extração. A seleção e coleta das amostras ocorreu de forma aleatória, sendo que para o seu número total foi utilizado o cálculo amostral de população infinita (Hennekens \& Buring 1987).

As amostras foram submetidas à extração de DNA com o kit comercial (Wizard ${ }^{\circledR}$ Genomic DNA Purification Kit-Promega), seguindo instruções do fabricante, com modificações na etapa de lise, de acordo com Moré et al. (2011). Após a extração, foi estimada a concentração de DNA em cada amostra através da medição com luz ultravioleta (UV) a 260nm de absorbância, com adequação da concentração mínima de $100 \mathrm{ng} / \mu \mathrm{l}$ de DNA em cada amostra, sendo estas armazenadas a $-20^{\circ} \mathrm{C}$ até a sua utilização (Eslami et al. 2014). Para detecção do agente Sarcocystis spp. através da amplificação parcial do gene 18S rRNA, utilizou-se as sequências de Sarco F-'CGCAAATTACCCAATCCTGA' e Sarco R-'ATTTCTCATAAGGTGCAGGAG'. A reação de PCR foi realizada em volume final de $25 \mu$ l, contendo $5 \mu$ l de tampão, $100 \mathrm{ng}$ de cada iniciador, $10 \mathrm{mM}$ de deoxinucleotídeo trifosfato (dNTPs), uma unidade de Taq DNA Polimerase GoTaq ${ }^{\circledR}$ (Hot Start Polymerase, Promega, Madison, WI, USA) e 100ng de DNA total utilizado como molde. Para amplificação do DNA, foram utilizados 35 ciclos com desnaturação inicial $94^{\circ} \mathrm{C}$ por 5 minutos, desnaturação $94^{\circ} \mathrm{C}$ por 45 segundos, anelamento $55^{\circ} \mathrm{C}$ por 45 segundos, extensão $72^{\circ} \mathrm{C}$ por 45 segundos, seguido por extensão final a $72^{\circ} \mathrm{C}$ por 5 minutos. Os produtos da PCR foram visualizados por eletroforese em gel de agarose a 1\% em transluminador UV. Para controle positivo foi utilizado uma amostra de coração bovino sabidamente positivo para a presença de cistos de Sarcocystis spp. Foram consideradas positivas amostras com fragmentos de $700 \mathrm{pb}$.

Para o desenvolvimento da RFLP foram utilizadas as enzimas de restrição $B c l I^{\circledR}$ (Promega, Madison, WI, USA) e Rsa $I^{\circledR}$ (Promega, Madison, WI, USA) para diferenciação das espécies de Sarcocystis cruzi, S. hirsuta e $S$. hominis positivas pela PCR. Devido à presença de carne das espécies bovina e suína nos salames coloniais, a presença da espécie $S$. suihominis também foi pesquisada, utilizando a enzima de restrição Alu $I^{\circledR}$ (Promega, Madison, WI, USA). Conforme Yang et al. (2002), fragmentos de $S$. cruzi são cortados apenas com a enzima Rsa I, S. hirsuta é cortado pelas enzimas Bcl I e Rsa $I$ e $S$. hominis permanece sem cortes com ambas enzimas. Para a análise de restrição com a enzima $B c l$ I, uma reação com $20 \mu \mathrm{l}$ de volume final foi preparada, contendo $5 \mu$ l de produto de PCR, $2 \mathrm{U}$ $B s a, 5 \mathrm{U}$ de $B c I, 2 \mu \mathrm{l}$ de tampão e $12 \mu \mathrm{l}$ de água miliQ, com incubação a $55^{\circ} \mathrm{C}$ por 60 minutos. Para a enzima Rsa I, foi realizada uma reação com volume final de $20 \mu \mathrm{l}$, com $5 \mu \mathrm{l}$ de produto de PCR, $2 \mathrm{U}$ de $B s a$, $5 \mathrm{U}$ de $R s a, 2 \mu \mathrm{l}$ de tampão e $12 \mu \mathrm{l}$ de água miliQ, sendo as amostras incubadas a $37^{\circ} \mathrm{C}$ por 4 horas. Para a enzima de restrição Alu I, uma reação com volume final $27 \mu \mathrm{l}$, foram adicionados $5 \mu \mathrm{l}$ de produto da PCR, $2 \mu \mathrm{l}$ de tampão, $20 \mu \mathrm{l}$ de Alu e $18 \mu \mathrm{l}$ de água miliQ, sendo incubado a $37^{\circ} \mathrm{C}$ por 2 horas. Os resultados foram visualizados em gel de agarose $2 \%$.

Todos os dados foram analisados utilizando o programa SAS (SAS Institute Inc., Cary, NC). Os resultados foram analisados pelo teste de Qui-quadrado, com nível de significância de $\mathrm{p} \leq 0,05$. 


\section{RESULTADOS E DISCUSSÃO}

Do total das 375 amostras de carne bovina, 64 (17\%, IC: $13,4-21,3$ ) foram positivas para a presença do DNA do Sarcocystis spp. As amostras de filé mignon, carne moída e de salame colonial, apresentaram positividade de 5,6\% (7/125, IC: 2,3-11,3), 12,8\% (16/125, IC: 7,5-19,9) e 32,8\% (41/125, IC: $24,7-41,8$ ) respectivamente (Quadro 1 ). Quanto à presença de DNA de Sarcocystis spp., houve diferença significativa $(\mathrm{p} \leq 0,05)$, entre a frequência encontrada para as espécies de Sarcocystis hirsuta e $S$. hominis, sendo 93,7\% (60/64, IC: 84,7-98,2) para $S$. hirsuta e 6,3\% (4/64, IC: 1,72-15,23) para S. hominis, do total das amostras positivas encontradas, sendo a diferenciação destas espécies realizada através da técnica de RFLP (Fig.1). Todas as amostras de salame colonial positivas na PCR foram posteriormente analisadas por RFLP com a enzima Alu I apresentando resultado negativo, sugerindo assim que a espécie $S$. suihominis não esteve presente na amostragem testada. 0 controle positivo foi caracterizado como S. cruzi, sendo cortado apenas pela enzima Rsa I (Fig.1).

A detecção e identificação de patógenos nos alimentos são cruciais para a saúde pública. Nesse sentido, o desenvolvimento da biologia molecular tem contribuído para melhorar os métodos de diagnóstico e a caracterização das espécies de Sarcocystis spp. Comparado com outros métodos de diagnóstico, as técnicas moleculares são métodos mais precisos para identificação dos agentes causadores de diversas doenças (Stojecki et al. 2012). No sul do Brasil, bovinos clinicamente saudáveis apresentam alta prevalência de sarcocistose, sendo o S. cruzi a espécie mais frequente (Ruas et al. 2001). Conforme estudos anteriores, cerca de $90 \%$ dos animais adultos são positivos em diversos países, sendo o músculo cardíaco o tecido mais afetado (Böttner et al. 1987, Dubey et al. 1989, Nourani et al. 2010, Bucca et al. 2011, Moré et al. 2011). Nas amostras de filé mignon bovino a frequência de detecção do DNA do Sarcocystis foi de 5,6\% (7/125), porém não existem pesquisas específicas para este corte de carne. Assim, devido sua utilização na produção do Carpaccio, é importante avaliar a ocorrência deste protozoário nessa porção muscular.

Em pesquisas realizadas por Pena et al. (2001) com quibe cru na cidade de São Paulo, 100\% (50/50) das amostras foram positivas para Sarcocystis spp., salientando que o preparo de quibe cru com carne bovina, pode ser uma fonte de transmissão de $S$. hominis para humanos. No estado do Rio Grande Sul, Ruas et al. (2001), determinaram uma elevada

Quadro 1. Ocorrência das espécies de Sarcocystis spp. testadas por PCR-RFLP em amostras de filé mignon, carne moída e salame colonial, coletadas em estabelecimentos comerciais e feiras livres na cidade de Santa Maria, Rio Grande do Sul

\begin{tabular}{lccc}
\hline & $\begin{array}{c}\text { Filé mignon } \\
(\%)\end{array}$ & $\begin{array}{c}\text { Carne moída } \\
(\%)\end{array}$ & $\begin{array}{c}\text { Salame colonial } \\
(\%)\end{array}$ \\
\hline $\begin{array}{l}\text { Sarcocystis } \\
\text { hirsuta }\end{array}$ & $7 / 125(5,6)$ & $15 / 125(12)$ & $38 / 125(30,4)$ \\
$\begin{array}{l}\text { Sarcocystis } \\
\text { hominis } \\
\text { Sarcocystis } \\
\text { suihominis }\end{array}$ & $0 / 125(0)$ & $1 / 125(0,8)$ & $3 / 125(2,4)$ \\
TOTAL & $0 / 125(0)$ & $0 / 125(0)$ & $0 / 125(0)$ \\
& $7 / 125(5,6)$ & $16 / 125(12,8)$ & $41 / 125(32,8)$
\end{tabular}

ocorrência de Sarcocystis spp. em bovinos clinicamente sadios, detectando através de exame direto, cistos teciduais em diferentes porções musculares analisadas. A mistura de diferentes porções musculares pode favorecer um maior índice de detecção parasitária nas amostras de carne moída $(12,8 \%)$, quando comparado com os resultados encontrados nas amostras de filé mignon ( $5,6 \%)$, porém esta diferença não apresentou significância estatística $(\mathrm{p} \geq 0,05)$.

A detecção de 32,8\% (41/125) em amostras de salame colonial sugere que os animais que deram origem à matéria-prima utilizada na fabricação destes embutidos, eram criados de forma desconhecida, provavelmente permitindo livre acesso de outros animais, entre eles possíveis hospedeiros definitivos às instalações de criação (Dubey \& Lindsay 2006). Porém a presença do protozoário não significa necessariamente risco potencial para infecção aos humanos, já que a utilização adequada de sais de cura na fabricação dos embutidos e o processo de defumação podem diminuir a viabilidade de infecção dos cistos (Kijlstra \& Jongert 2009). A prevalência mundial de S. suihominis geralmente é baixa (Saito et al. 1998), porém é importante a pesquisa do seu DNA em amostras que contenham carne suína, pois é um parasita que pode circular entre seres humanos e suínos, que apresenta o homem como seu hospedeiro definitivo e que também pode desenvolver sinais clínicos (Dubey \& Lindsay 2006). Neste trabalho não foi detectada sua presença nas amostras de salame colonial, que são de origem mista, ou seja, são produzidos com carne de bovinos e suínos.

Das amostras positivas, $S$. hirsuta foi caracterizado em $93,7 \%(60 / 64)$ e $S$. hominis em 6,3\% (4/64) das amostras, apresentando diferença de detecção significativa entre elas $(p \leq 0,05)$. Dessa maneira, pode ser sugerido que felinos e humanos que são seus hospedeiros definitivos, possuem contato e livre acesso às instalações dos bovinos, que são os seus hospedeiros intemediários (Fayer 2004). A ocorrência do $S$. hominis pode ser um fator de risco que contribui para a contaminação humana, uma vez que a infecção do hospedeiro definitivo se dá através da ingestão de carne crua ou mal cozida contendo os sarcocistos (Ruas et al. 2001). Devido ao potencial zoonótico, associado à falta de esclarecimentos na sua patogenicidade, é importante a sua prevenção através do cozimento a $65^{\circ} \mathrm{C}$ ou pelo congelamento a $-4^{\circ} \mathrm{C}$ dos produtos cárneos a serem empregados na alimentação humana (Srivastava et al. 1986).

0 diagnóstico molecular tem sido amplamente utilizado na detecção e caracterização de diversas espécies, incluindo o Sarcocystis spp. (Yang et al. 2002). A PCR é uma alternativa que pode ser empregada em amostras processadas, congeladas ou que tenham sofrido alguma ação capaz de tornar inviável a identificação dos cistos através de microscopia, apesar de geralmente apresentar uma sensibilidade menor quando comparada com o exame microscópico direto (Moré et al. 2011). A técnica baseada em RFLP pode ser aplicada para diferenciar espécies morfologicamente semelhantes de Sarcocystis spp. Apresentando menor custo e maior agilidade na obtenção de resultados quando em comparação ao sequenciamento de DNA (Yang et al. 2002). A identificação das espécies é importante, principalmente, pela relevância desta parasitose na área de saúde pública, pois o homem pode adquirir a doença através da ingestão de carne crua ou mal cozida (Fayer 2004). 


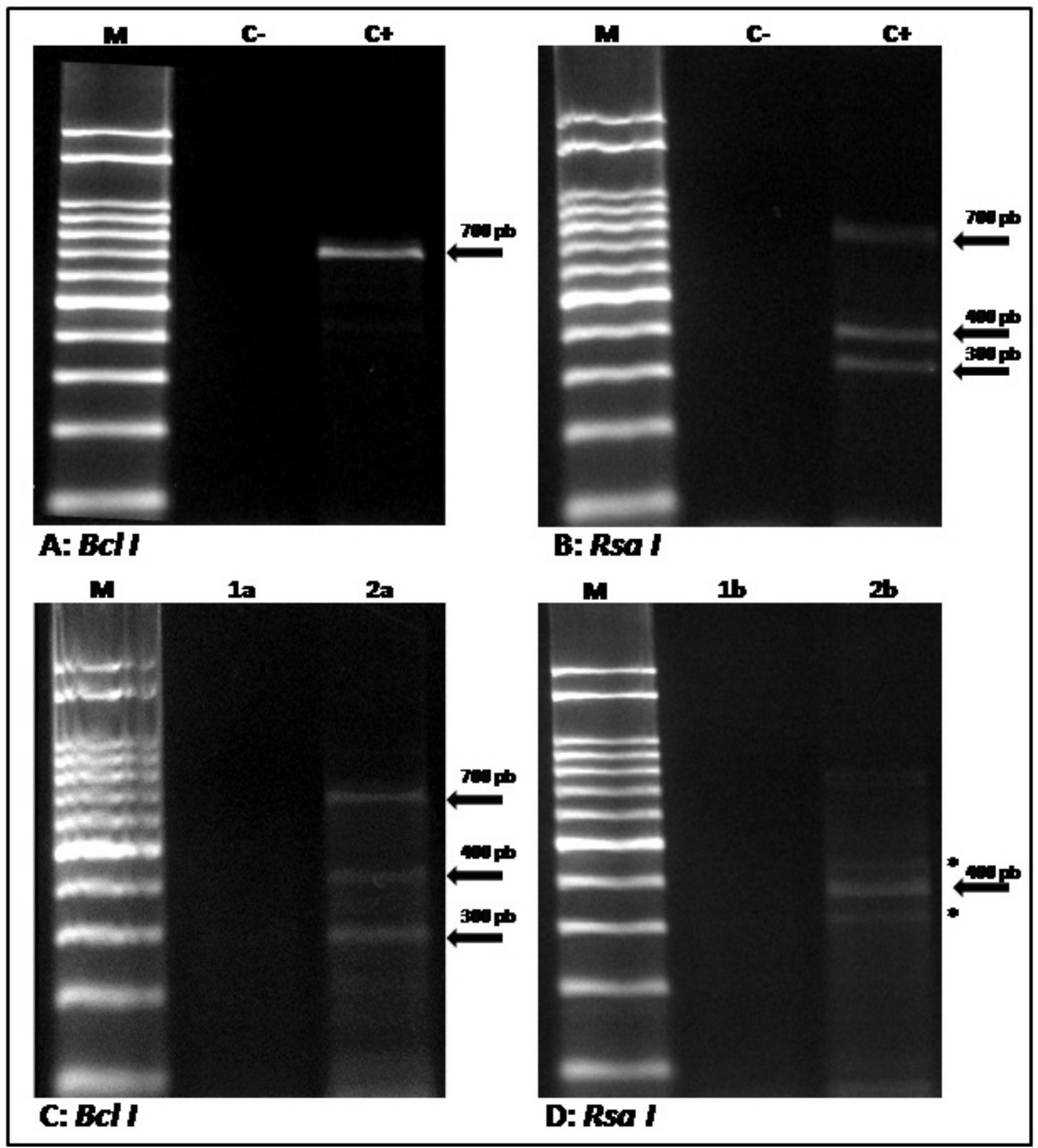

Fig.1. (A e C) Análise de polimorfismo no comprimento do fragmento de restrição (RFLP) com as enzimas Bcl I e (B e D) Rsa I. Marcador de DNA de 100pb (M), controle negativo (C-), Sarcocystis cruzi cortado apenas por Rsa I (C+). Sarcocystis hominis sem cortes em ambas as enzimas (1a e 1b). Sarcocystis hirsuta cortado com as duas enzimas (2a e 2b). * Fragmentos de dois tamanhos diferentes migraram em conjunto.

\section{CONCLUSÕES}

Os resultados encontrados revelam a presença dos parasitas Sarcocystis spp. em amostras de filé mignon bovino, carne moída bovina e salame colonial, sendo caracterizados pela RFLP como Sarcocystis hirsuta e S. hominis.

A detecção de $S$. hominis pode ser um fator de risco para a contaminação humana, através da ingestão de carne crua ou mal cozida que contenham sarcocistos.

Entre os produtos cárneos testados, o salame colonial apresentou maior ocorrência de amostras positivas, sendo S. hirsuta a espécie mais frequentemente detectada. Porém, a presença do DNA deste protozoário não significa necessariamente potencial de infecção aos humanos, pois cuidados nos processos de fabricação podem reduzir a viabilidade dos cistos.

\section{REFERÊNCIAS}

Böttner A., Charleston W.A., Pomroy W.E. \& Rommel M. 1987. The prevalence and identity of Sarcocystis in beef cattle in New Zealand. Vet. Parasitol. 24(3/4):157-168. http://dx.doi.org/10.1016/0304-4017(87)90036-7. PMid:3113040.

Braga H.F. \& Ferreira I.M. 2013. Quibe cru: qualidade sanitária e perigo à saúde. Revta Bras. Pesq. Saude 15:123-129. 
Bucca M., Brianti E., Giuffrida A., Ziino G., Cicciari S. \& Panebianco A. 2011. Prevalence and distribution of Sarcocystis spp. cysts in several muscles of cattle slaughtered in Sicily, southern Italy. Food Control 22(1):105-108. http://dx.doi.org/10.1016/j.foodcont.2010.05.015.

Dubey J.P. \& Lindsay D.S. 2006. Neosporosis, toxoplasmosis, and sarcocystosis in ruminants. Vet. Clin. N. Am., Food Anim. Pract. 22(3):645-671. http:// dx.doi.org/10.1016/j.cvfa.2006.08.001. PMid:17071358.

Dubey J.P., Speer C.A. \& Fayer R. 1989. Sarcocystosis of Animals and Man. CRC Press, Boca Raton, Florida. 215p.

Eslami G., Zohourtabar A. \& Mehrizi S.R. 2014. First molecular identification of Sarcocystis hirsuta in Iranian beef: a case report. J. Food Qual. Hazards Control 1:32-34.

Fayer R. 2004. Sarcocystis spp. in human infections. Clin. Microbiol. Rev. 17(4):894-902. http://dx.doi.org/10.1128/CMR.17.4.894-902.2004. PMid:15489353.

Germano P.M.L. \& Germano M.I.S. 2001. Higiene e Vigilância Sanitária de Alimentos. Varela, São Paulo. 655p.

Hennekens C.H. \& Buring J.E. 1987. Epidemiology in Medicine. Little Brown Co., Boston. 383p.

Italiano C.M., Wong K.T., AbuBakar S., Lau Y.L., Ramli N., Syed Omar S.F., Kahar Bador M. \& Tan C.T. 2014. Sarcocystis nesbitti causes acute, relapsing febrile myositis with a high attack rate: description of a large outbreak of muscular sarcocystosis in Pangkor Island, Malaysia, 2012. PLoS Negl. Trop. Dis. 8(5):e2876. http://dx.doi.org/10.1371/journal.pntd.0002876. PMid:24854350.

Kijlstra A. \& Jongert E. 2009. Toxoplasma safe meat: close to reality? Trends Parasitol. 25(1):18-22. http://dx.doi.org/10.1016/j.pt.2008.09.008. PMid:18951847.

Lucquin I., Zagorec M., Champomier-Vergès M. \& Chaillou S. 2012. Fingerprint of lactic acid bacteria population in beef carpaccio is infuenced by storage process and seasonal changes. Food Microbiol. 29(2):187-196. http:// dx.doi.org/10.1016/j.fm.2011.08.001. PMid:22202872.

Moré G., Abrahamovich P., Jurado S., Bacigalupe D., Marin J.C., Rambeaud M., Venturini L. \& Venturini M.C. 2011. Prevalence of Sarcocystis spp. in Argentinean cattle. Vet. Parasitol. 177(1/2):162-165. http://dx.doi. org/10.1016/j.vetpar.2010.11.036. PMid:21168276.
Nourani H., Matin S., Nouri A. \& Azizi H. 2010. Prevalence of thin-walled Sarcocystis cruzi and thick-walled Sarcocystis hirsute or Sarcocystis hominis from cattle in Iran. Trop. Anim. Health Prod. 42(6):1225-1227. http:// dx.doi.org/10.1007/s11250-010-9552-z. PMid:20379775.

Pena H.F.J., Ogassawara S. \& Sinhorini I.L. 2001. Occurrence of cattle Sarcocystis species in raw kibbe from arabian food establishments in the city of São Paulo, Brazil, and experimental transmission to humans. J. Parasitol. 87(6):14591465. http://dx.doi.org/10.1645/0022-3395(2001)087[1459:00CSSI]2 .0.CO;2. PMid:11780838.

Reys L. 2008. Parasitologia. 4aㅡ ed. Guanabara Koogan, Rio de Janeiro. 888p.

Rommel M. 1985. Sarcocystosis of domestic animals and humans. In Pract. 7(5):158-160. http://dx.doi.org/10.1136/inpract.7.5.158. PMid:3932221.

Ruas J.L., Cunha C.W. \& Silva S.S. 2001. Prevalência de Sarcocystis spp. (Lankester, 1882) em bovinos clinicamente sadios, da região do Rio Grande do Sul, Brasil. Revta Bras. Agrociênc. 7:227-230.

Saito M., Shibata Y., Ohno A., Kubo M., Shimura K. \& Itagaki H. 1998. Sarcocystis suihominis detected for the first time from pigs in Japan. J. Vet. Med. Sci. 60(3):307-309. http://dx.doi.org/10.1292/jvms.60.307. PMid:9560777.

Silva C.D.A., Savariz F.C., Follmann H.D.M., Nuñes L., Chapla V.M. \& Silva C.F.D.A. 2011. Análise físico-química de salames coloniais comercializados no município de Toledo, Estado do Paraná. Acta Sci. Technol. 33(3):331-336. http://dx.doi.org/10.4025/actascitechnol.v33i3.7775.

Srivastava P.S., Saha A.K. \& Sinha S.R.P. 1986. Effects of heating and freezing on the viability of sarcocysts of Sarcocystis levinei from cardiac tissues of buffaloes. Vet. Parasitol. 19(3/4):329-332. http://dx.doi.org/10.1016/03044017(86)90080-4. PMid:3085325.

Stojecki K., Karamon J., Sroka J. \& Cencek T. 2012. Molecular diagnostics of Sarcocystis spp. infections. Pol. J. Vet. Sci. 15(3):589-596. PMid:23214385.

Yang Z.Q., Li Q.Q., Zuo Y.X., Chen X.W., Chen Y.J., Nie L., Wei C.G., Zen J.S., Attwood S.W., Zhang X.Z. \& Zhang Y.P. 2002. Characterization of Sarcocystis species in domestic animals using a PCR-RFLP analysis of variation in the 18S rRNA gene: a cost-effective and simple technique for routine species identification. Exp. Parasitol.102(3/4):212-217.http://dx.doi.org/10.1016/ S0014-4894(03)00033-X. PMid:12856319. 